\title{
Outsourcing and role stress: An empirical study of hotel spa managers
}

\author{
Demian Hodari \\ École hôtelière de Lausanne \\ Veronica Waldthausen \\ École hôtelière de Lausanne \\ Michael Sturmanb \\ Cornell University
}

\begin{abstract}
Hotel owners and managers are increasingly outsourcing their spas to specialist firms that oversee the spa's operations and personnel. In such spas the assume the role of boundary spanners as they are responsible for overseeing the operational relationship between the hotel and spa companies. In this role, they are responsible for trying to satisfy the hotel and spa companies' often contradictory expectations while also often adhering to two sets of operating guidelines. As a result, they may experience different levels of role conflict and role ambiguity than spa managers who oversee spas managed by the hotel. The results of a questionnaire completed by 166 hotel spa managers from spas managed by hotels and those managed by third parties found greater levels of these role stressors in managers of outsourced hotel spas. Based on these findings, research suggestions and managerial implications are discussed.
\end{abstract}

\section{Introduction}

Competitive pressures force organizations to find ways to reduce their costs and/or improve their products and services. One way they do so is by outsourcing those activities which are peripheral to their primary business (Gilley and Rasheed, 2000). This allows them to focus on their core competencies rather than on the non-value-adding activities which a contracted, specialized service provider can likely provide more efficiently and/or effectively (Jones, 1997). Outsourcing can, however, be risky as such decisions can be costly to reverse (Quelin and Duhamel, 2003) and may result in the loss of important competencies (Bettis et al., 1992). It can also have a detrimental impact on management personnel, particularly with regards to higher turnover, lower productivity and poor morale (Benson, 1998; Stamper and Johlke, 2003). This maybe because managers of the outsourced department must assume the challenging role of boundary spanners as they coordinate the client and service provider's inter-organizational relationship (Aldrich and Herker, 1977; Nygaard and Dahlstrom, 2002).

Boundary spanners are a distinct and growing proportion of many organizations' labor forces (Singh, 1998). They are a particularly interesting group to study since their job-related experiences often require them to work away from the firm, handle non-routine tasks and encounter conflicting role expectations (Stamper and Johlke, 2003). Boundary-spanning managers may therefore be particularly susceptible to the difficulties associated with increased task interdependency (Karasek, 1979; Thompson, 1967) since other individuals, organizational unit and/or firms can influence their ability to accomplish their work responsibilities. 
The need to interact with a wider set of colleagues and superiors who have divergent demands and expectations often results in boundary spanners experiencing high levels of work-related stress (Kahn et al., 1964; Singh et al., 1996; Solli-Saether, 2011; Stamper and Johlke, 2003). The uncertainty and conflict inherent to boundary spanning (Singh, 1993) are direct antecedents of two important role stressors: role conflict and role ambiguity (Kahn et al., 1964; Singh and Rhoads, 1991). Understanding the prevalence and causes of these stressors is important for organizations since previous research has established that they are correlated with low job satisfaction, high propensity to leave, lower job performance, and decreased service quality and organizational performance (e.g., Brown and Peterson, 1993; Kahn et al., 1964; Walker et al., 1975; Onyemah, 2008). Thus, while outsourcing can at first seem like a prudent strategic move when the task is not a core competency, the negative consequences of such a decision may outweigh the benefits. It is thus important to study the potential negative consequences associated with boundary-spanning roles so that research can help practitioners make evidence-based decisions (e.g., Rousseau, 2006; Rousseau \& McCarthy, 2007) regarding outsourcing decisions.

One context where the issues of outsourcing and boundary spanning are highly salient is within the luxury hotel industry, and specifically the decisions many hotels make on whether to manage their own spa or outsource it to a specialist third-party. Hotels frequently consign the operations and management of their spas to specialized companies because hotel spas rarely provide the financial returns that hotel owners and managers require (Mandelbaum and Lerner, 2008). For example, one study found that the average hotel spa profit margins are about $25 \%$ lower than that of other hotel departments (Mandelbaum and Lerner, 2008). Although this may be because spas have traditionally been seen as a peripheral service rather than a profit center (Anderson, 2011), it has also been linked to the fact that hoteliers have not generally understood the complexity of spa operations and the corresponding management implications (Glover, 2012). At the same time, spa companies are interested in managing hotel spas because they are typically more profitable than other types of spas (ISPA, 2012).

The International Spa Association defines spas as "places devoted to enhancing overall wellbeing through a variety of professional services that encourage the renewal of mind, body, and spirit" (ISPA, n.d.). Garrow (2008) notes, however, that for benchmarking purposes spa definitions should also include references to water-based therapies and a relaxing environment as doing so helps to ensure that non-spa businesses such as beauty salons, hotel massage services, clinics and other types of businesses that do not offer spa treatments are not confused with 'true spas.' As this study focuses on hotel spas it defines them as being located within a resort or hotel, delivering professional spa services, including fit $\neg$ ness and wellness components, and possibly offering spa cuisine (see Dusseau and Brennan, 2008; PKF, 2012 Trends Report).

This study thus investigates whether hotel spa managers who work with a third-party management company experience different levels of role conflict and role ambiguity than spa managers who work in spas which are proprietarily managed by the hotel. It addresses several identified research gaps, including the human resource management implications of outsourcing (Fisher et al., 2008) and outsourcing's impact in the hotel industry (Gonzalez et al., 2011; Hemmington and King, 2000). Furthermore, despite the importance of spas to the luxury hotel industry, and the notable mix of outsourced and non-outsourced spas, there is no research on the human resource implications of outsourcing in hotel spas. There is also a real practical need for research within this specific context since the difficulty in attracting and retaining qualified spa managers is one of the spa industry's most pressing concerns (SRI International, 2012). Furthermore, role conflict and role ambiguity may ultimately 
exacerbate this problem (e.g., Churchill et al., 1976; Onyemah, 2008; Rizzo et al., 1970) and thus lead to higher recruitment and training costs (Walker et al., 1975).

\section{Outsourcing and hotel spas}

\subsection{The reason for outsourcing}

Outsourcing has evolved over the past few decades as the original focus on manufacturing and information technology has given way to a wider array of processes and services that can be run by, or with, a third party (Gilley and Rasheed, 2000). Outsourcing generally refers to a choice companies make about the disintegration of their activities. The term is often used as a synonym for both sub-contracting and externalization and is often explained as a "make or buy" decision (Gilley and Rasheed, 2000). For some, outsourcing refers to the purchase of an item or service that the firm itself is unable to produce (e.g., Van Mieghem, 1999). Others consider outsourcing to be the sub-contracting of activities that the firm no longer wishes to perform in-house (e.g., Lei and Hitt, 1995; Rothery and Robertson, 1995). Therefore, for the purposes of this paper, we define an outsourcing relationship as when a vendor provides its skills, knowledge, technology, service and/or manpower to a client for an established price and period in order to perform functions that the client cannot, or wishes to not, perform (Adler, 2003).

The decision to outsource may be made for both tactical and strategic reasons (Sanders et al., 2007). Tactical outsourcing is usually based on the need to reduce costs, which can be achieved through the more efficient service-provision by specialized firms. Strategic outsourcing, meanwhile, implies not only cost savings but also improved operations and can involve peripheral activities as well as those that contribute to the firm's added value (Quelin and Duhamel, 2003). Given the different reasons for outsourcing and the need to align the often divergent interests of the involved parties, numerous outsourcing models have been developed (Lambert et al., 1996).

Some typical outsourcing relationships include franchising, management contracts, leasing and contracting, all of which are prevalent in the hotel industry as well (DeRoos, 2011). While there are important structural and legal differences between these various relationships, and it is beyond the scope of this study to review these, common to all of them is that managers in these situations must often play a boundary spanning role.

\subsection{Outsourcing in the luxury hotel industry}

Upscale and luxury hotel companies are increasingly outsourcing their auxiliary services in order to address the challenges that emanate from the sector's high labor intensity, volatile demand patterns, and need to provide and manage multiple complex services within one establishment (Donada and Nogatchewsky, 2009; Lamminmaki, 2011). While the outsourcing of a property's food and beverage units (Hemmington and King, 2000) and information technology services (Gonzalez et al., 2011) have been relatively common for several decades, current trends indicate that hotels are also more frequently outsourcing their leisure activities (Espino- Rodriguez and Padron-Robaina, 2005).

High quality leisure activities are becoming a priority for guests and a means for improving a hotel's competitiveness (Espino- Rodriguez and Gil-Palida, 2005). Yet despite its growing strategic importance, they are also the third most outsourced area in hotels (Espino-Rodriguez and PadronRobaina, 2005). This is because leisure activities require specialized personnel which many hotels lack, making it difficult for them to successfully offer these activities in-house even if they have the appropriate physical facilities (Espino-Rodriguez and Gil-Palida, 2005).

Hotels which outsource such activities expect to provide their guests with superior service quality levels since these expert providers should be better able to select, train and manage the worker as this leisure service is their core activity (Espino- Rodriguez and Gil-Palida, 2005). This is particularly 
relevant for spas as they are among the most labor intensive businesses in the hospitality industry (Tabacchi, 2010), with labor in many cases con $\neg$ stituting $70 \%$ of a spa's direct operating costs (Mandelbaum and Lerner, 2008). Additionally, a successful spa also often requires managers to have a wellness or therapist background (Bjurstam and Cohen, 2008; ISPA, 2012; SRI International, 2012), which is often a very different skills set than possessed by those in the hotel industry. Hotels are thus expected to continue to increasingly out-sourcing spa departments to specialized spa management firms in order to help solve these challenges (Anderson, 2011; Burgess, 2011; Glover, 2012; Singer, 2011).

As noted above, there are many different possible outsourcing relationships, and indeed the spa industry has a wide array of out-sourcing arrangements. On the one end, hotels can practice 'full outsourcing' by completely outsourcing all aspects of the spa to external firms. Essentially, these hotel owners/companies simply subcontract space in their hotel to the external firm in exchange for a rental fee (Andrews, 2009). In such cases, the hotel here has little-to-no say about the spa's operations or management in this lease arrangement. This can be problematic, however, because hotel guests consider the spas as part of the hotel and tend to blame the latter for poor spa experiences (Glover, 2012). As the person responsible for both the spa and its relationship with the hotel, this is likely to create a difficult situation for the boundary-spanning spa manager.

Hotels may retain a stronger, albeit still relatively small, say in the spa's operations and/or management when they opt for a management contract. In this arrangement, the spa operator generally charges the hotel a flat fee and a percentage of the spa's sales and/or profits (Glover, 2012). In this situation, the hotel's management is able to play a greater role in decisions affecting the spa's operations and management, including the role of the spa manager, and as such the latter is more clearly accountable to both entities.

Hotels which wish to maintain even greater control (or give up control for a shorter period) may prefer to only outsource parts of the operation or management (Andrews, 2009; Glover, 2012). This is often done through the use of a 'Management Assistance Contract.' In such cases, the spa operator is often a consulting company, providing management services until a qualified spa director who will work directly for the hotel can be hired and/or trained. This allows the hotel to retain administrative control of its spa operations and its trained spa staff (Andrews, 2009). Here, the spa company oversees the staff and takes charge of the technical operations. The spa staff is on the hotel's payroll, but the spa manager/director is monitored and directed by the spa company which technically manages the operation.

In all of these outsourced relationships, one of the spa manager's critical roles is to establish and maintain a successful relationship between the hotel and spa companies. Because of this important role, spa industry executives are highly concerned about the factors that lead qualified spa managers to leave organizations and the industry, including most notably difficult working conditions and low job satisfaction (SRI International, 2012). More specifically, their high rate of turnover has been blamed on poor and infrequent communication, insufficient training and support, and a lack of clear instructions (Preston, 2011). One could perhaps argue that this is simply the nature of the spa manager's job and little can be done to improve the situation; however, all of the challenges noted above are also the archetypical challenges associated with boundary spanning and/or outsourcing (Kahn et al., 1964; Rizzo et al., 1970; Rogers and Molnar, 1976; Ilgen and Hollenbeck, 1991). Because higher turnover and lower job satisfaction have been associated with the outsourcing of other hotel departments (Lam and Han, 2005), a concern that the outsourcing of spas could have similar results is warranted.

One reason why the retention problem may be particularly high in hotel spas, and more specifically in those that are outsourced, is due to the particularly challenging work environment. While hotel spa managers may benefit from support services provided by other hotel departments, they also 
require additional skills in order to function in a corporate environment, follow standard operating procedures, and interact with the hotel's General Manager and/or corporate-level hotel executives who are rarely knowledgeable about spas and often do not demonstrate sufficient recognition for spas and their personnel (Glover, 2012; SRI International, 2012).

Furthermore, hotel spa managers face conflicting messages in terms of what is expected of them due to the impact and involvement of multiple stakeholders with somewhat incompatible priorities. For example, hotel general managers are primarily focused on the hotel's operating performance (Ladkin, 1999). At the same time, marketing departments see spas as a way to generate occupancy rather than as profit centers (Gibson, 2008) and the revenue management directors generally identify spas as a way to increase rates (Singer and Monteson, 2006). The situation is exacerbated in outsourced hotel spas due to the additional expectations and demands of the spa company. For example, because spa companies often generate higher returns from their branded products rather than services (Glover, 2012), spa managers must also focus on these sales-related activities, even if they are of little benefit to the hotel.

In sum, while there are many potential strategic and tactical advantages to outsourcing hotel spas, the delivery of peripheral hotel services by third parties can become complex. The hotel spa manager is thus in a notably challenging boundary spanning role, due to conflicting organizational demands, cultures, structures, and management styles (Hemmington and King, 2000).

\section{The effects of outsourcing and boundary-spanning on hotel spa managers}

One of the key reasons firms outsource is that they lack the capabilities to develop their own qualified staff (Adler, 2003). This can be particularly difficult because organizations which outsource certain functions or departments must be concerned about employing and retaining individuals who are able to successfully operate at the challenging intersection of two organizations (Fisher et al., 2008). Indeed, managers responsible for outsourced functions have reported that they often do not have the skills or proper training to manage the inter-organizational relationship and the extensive communication between them (Adler, 2003). The lack of such necessary abilities has been found to produce greater levels of work-related stress in boundary-spanners such as sales agents and retail employees (Singh, 1993; Stamper and Johlke, 2003).

Performing outsourced work on a client's site can be especially problematic as it often creates complex supervisory and reporting relationships (Fisher et al., 2008) which can lead to increased role ambiguity (Rizzo et al., 1970) since employees maybe unsure about the work activities for which they are responsible. Similarly, out-sourcing may result in higher levels of role conflict since employees may face incompatible job demands from different stakeholders making it difficult to satisfy all concerned (Kahn et al., 1964; House and Rizzo, 1972; Nygaard and Dahlstrom, 2002).

\subsection{Role conflict}

Role conflict is defined as ".. .the simultaneous occurrence of two (or more) sets of pressures such that compliance with one would make more difficult compliance with the other" (Kahn et al., 1964, p. 19). It thus refers to the degree of incompatibility between the expectations of multiple parties (Rizzo et al., 1970; Wong et al., 2007). It is particularly prevalent when the employee is unable to satisfy irreconcilable demands from multiple role senders such as superiors, colleagues and customers (Fields, 2002; Kahn et al., 1964; Onyemah, 2008; Walker et al., 1975).

The need to coordinate activities across organizational boundaries has long been established as a source of role conflict (Corwin, 1969). Individuals who must frequently coordinate with persons 
outside their organization encounter more interdependencies (Wong et al., 2007) and thus experience much higher levels of role conflict than individuals who receive demands from only internal sources (Kahn et al., 1964; Miles, 1976b; Nygaard and Dahlstrom, 2002; Solli-Saether, 2011). Such boundary spanners may be especially susceptible to role conflict since they have little control over the people outside their organization with whom they must interact (White, 1974). The conflict potential for those in boundary-spanning roles also increases with the level of differentiation between the different units because more coordination and understanding is required (Miles, 1976a). Additionally, employees with such specialist positions also experience increased levels of role conflict as they must interact with a greater number of people in order to complete their job (Thompson, 1967).

Although they did not empirically test the prevalence of role conflict in outsourced situations, Fisher et al. (2008) did understandably posit that role conflict may occur if the employees in outsourced relationships perceive that what the client's expectations conflicts with the service provider's instructions. Furthermore, managers may have trouble meeting the demands of superiors from both organizations since these are often contradictory, creating a situation in which the manager is uncertain about how to achieve the different parties' goals and objectives (Singh, 1993). This lack of unity of command' has been correlated with higher levels of role conflict because the individual is charged with satisfying potentially incompatible requirements from different superiors (Rizzo et al., 1970).

Managers of outsourced hotel spas are responsible for the inter-organizational relationship between the hotel and spa company. They thus play a boundary-spanning role and are susceptible to many of the antecedents of role conflict, such as being in contact with multiple stakeholders and receiving contradictory demands from multiple parties, including those outside their own organization. Their task interdependency is also subject to elevated levels of conflict due to the more complex organizational structure in which they work. As such, we posit the following hypothesis:

Hypothesis 1. Hotel spa managers who work with an outsourced spa management company perceive significantly higher levels of role conflict than do hotel spa managers who work for proprietarily managed spas.

\subsection{Role ambiguity}

Role ambiguity arises when individuals are uncertain about how to perform their job and reach their assigned goals. It is generally due to a lack of information and instruction (Kahn et al., 1964), as well as unclear expectations of different role senders (Singh, 1998). This results in a lack of clarity about interdependency as managers are unsure about what they must coordinate and/or with whom they must do so (Wong et al., 2007). Ambiguity about role responsibilities is particularly high, therefore, when the individual must report to multiple stakeholders since there is a greater prevalence of contradictory instructions (Solli-Saether, 2011). This may be particularly problematic in outsourced situations, where an employer typically specifies the employee's job content and responsibilities and the host firm's operational requirements can contradict the specified role (Benson, 1998).

Role ambiguity is also prevalent when there is a lack of clarity and quality in subordinatesuperior communications (Kahn et al., 1964; Rizzo et al., 1970; Walker et al., 1975). The frequency of communication can similarly determine the level of role ambiguity (Ilgen and Hollenbeck, 1991; Walker et al., 1975). The more regular the communication between the employee and the supervisor, the greater the opportunity for the employee to learn about his/her role and the method of evaluation, and any behavior that is inconsistent with these expectations can thus be addressed more readily (Brown and Peterson, 1993). Role ambiguity may thus be greater in outsourced situations where the lack of communication between the parties (Jones, 1997) often leaves employees less informed and unclear about their tasks and duties (Taplin, 2007). 
Close supervision by managers can also reduce subordinates' role ambiguity because the proper level of assistance provides them with the confidence that they can complete their activities as desired by the supervisor (Walker et al., 1975). In outsourced hotel spas, however, the spa company's executives are rarely on site (Glover, 2012) and therefore less likely to be able to provide this level of supervision.

Providing employees with the opportunity to put forth their opinions about management decisions as well as the chance to participate in the decision-making process has also been demonstrated to lead to lower perceived levels of ambiguity (Ilgen andHollenbeck, 1991; Teas, 1980). When employees are able to influence their position, responsibilities and standards of evaluation, they are more likely to be familiar with and accepting of the specific requirements of their role, and this in turn can reduce their ambiguity (Ilgen and Hollenbeck, 1991). In spas, however, one of the most common problems faced by spa managers is their inability to influence the job description and responsibilities (Preston, 2011).

Given that outsourced hotel spa managers often report to individuals in two organizations, have less contact with their superiors, and are subject to less and poorer communication from them, they may be less clear about the expected behaviors associated with their work. As these are established causes of role ambiguity, we therefore propose the following hypothesis:

Hypothesis 2. Hotel spa managers who work with an outsourced spa management perceive significantly higher levels of role ambiguity than hotel spa managers who work for proprietarily managed spas.

\section{Methods}

\subsection{Samples and procedure}

To test the study's hypotheses, we collected data on the work situation and attitudes of spa managers. All of the spas surveyed were located within hotel properties and included both outsourced and non-outsourced spas. The researchers contacted executives from 16 hotel companies and 5 spa companies in order to gain access to their organizations' spa managers. Once the executives had approved the survey topic and reviewed the questionnaire itself, they were asked to forward the link to the Internet survey and an accompanying letter of introduction to their spa managers. As shown in Table 1, the data for this study was eventually collected with the collaboration of 11 international hotel companies and five spa management firms. Thus, the unit of analysis in our study is the spa manager, each representing a different organizational unit. There were no instances of more than one spa manager working at the same spa.

Questionnaires were distributed via e-mail by the participating firms to a total of $993 \mathrm{spa}$ managers, of whom 254 at least opened the survey link. Ultimately, a total of 166 usable responses were collected (note that of the other 88 , the respondents did not continue after the first few questions, thus leaving over $90 \%$ of the data missing and therefore making it impossible to validly apply missing data techniques). The final response rate was $17 \%$, which is above the average for internet questionnaires seeking responses from distinct organizational units, as such response rates usually lie between 6\% and 15\% (Lozar Manfreda et al., 2008) in general, and between 7\% and 10\% for hospitality related studies (Keegan and Lucas Rosemary, 2005; Paxson, 1995). While lower than ideal, the response rate was deemed more than satisfactory given our study involved international and cross-organizational sampling. 
Of the respondents, $71 \%$ were female, which is reflective of the demographics of the spa industry (SRI International, 2012). Seventy percent of the spa managers worked in proprietarily managed spas, whereas $30 \%$ had some type of outsourcing relationship.

Responses were collected from 45 different countries with most coming from the United States and China, which again reflects the industry situation given that these two countries have the most hotel and resort spas globally (Euromonitor International, 2012).

\subsection{Construct measurement}

The questionnaire was developed using previously developed and validated scales to measure the chosen constructs (role ambiguity and role conflict)

Table 1

Sampled companies.

\begin{tabular}{|c|c|c|c|c|}
\hline Company & Headquarter country & Number of distributed questionnaires & Number of surveys completed & Response rate (\%) \\
\hline Hotel Company A & Thailand & 31 & 7 & 23 \\
\hline Hotel Company B & Canada & 50 & 23 & 46 \\
\hline Hotel Company C & Hong Kong & 9 & 3 & 33 \\
\hline Hotel Company D & USA & 139 & 31 & 22 \\
\hline Hotel Company E & Switzerland & 70 & 6 & 9 \\
\hline Hotel Company F & Hong Kong & 27 & 9 & 33 \\
\hline Hotel Company G & England & 13 & 3 & 23 \\
\hline Hotel Company $\mathrm{H}$ & Hong Kong & 94 & 9 & 10 \\
\hline Hotel Company I & USA & 60 & 9 & 15 \\
\hline Hotel Company J & Switzerland & 69 & 6 & 9 \\
\hline Spa Company AA & England & 31 & 9 & 29 \\
\hline Spa Company BB & Malaysia & 63 & 17 & 27 \\
\hline Spa Company CC & USA & 50 & 3 & 6 \\
\hline Spa Company DD & Sweden & 200 & 8 & 4 \\
\hline Spa Company EE & Canada & 30 & 7 & 23 \\
\hline Spa Company FF & Thailand & 12 & 2 & 17 \\
\hline Spa Organization GG & Australia & 45 & 14 & 31 \\
\hline Total & & 993 & 166 & 17 \\
\hline
\end{tabular}

in order to increase the reliability, validity and generalizability of the survey (Saunders et al., 2009). The questionnaire consisted of a total of 48 items of which 35 came from previous questionnaires and remained unchanged. The scale used to measure role conflict and role ambiguity was created by Rizzo et al. (1970) and remains the most commonly used measurement tool when quantifying these two role stressors. Internal consistency above 0.7 has been consistently reported in earlier studies (e.g., Glazer and Beehr, 2005; Rizzo et al., 1970) illustrating adequate reliability of the measures (Nunnally, 1978).

\subsubsection{Role ambiguity}

The 14-item role ambiguity scale measures if the individual feels uncertain about how $\mathrm{s} / \mathrm{he}$ should perform his/her job due to a lack of information or instruction, and is uncertain of the consequences associated with his/her role. Sample items include "I have clear, planned goals and objectives for my job" and "I do not know if my work will be acceptable to my boss." As with the following two scales, it is based on a 7-point Likert scale. Cronbach's alpha for the scale was 0.80 .

\subsubsection{Role conflict}

The role conflict scale has 15 items and measures if the employees perceive that they are faced with incompatible job demands from different role senders and are unable to satisfy every role partner. Sample items include "I work with two or more groups who operate quite differently" and "I do things that are apt to be accepted by one person and not accepted by others." Cronbach alpha for the scale was 0.81 .

\subsubsection{Control variables}


In order to help rule out alternative explanations and to partial out effects associated with some individual and organizational characteristics, the remaining 17 questions captured characteristics of the spa managers and their associated (hotel or spa) companies. This included Quinn and Shepard's (1974) four item scale to capture job satisfaction. The remaining 13 questions were non-attitudinal in nature and were specifically developed for this questionnaire with the help of spa professionals (including spa managers/directors, spa company executives and spa consultants) from both hotel and spa companies who were interviewed about the spa industry and role of the spa manager prior to the survey construction. Six items related to the type of spa and its operation were included, as well as whether the spa was proprietarily managed or outsourced. Additional questions asked subjects about age, gender, experience, location and job title.

\subsection{Instrument validation}

\subsubsection{Pilot study}

In order to ensure content validity of the questionnaire, a pilot test was conducted whereby a small sample of spa managers, executives and consultants were given the questionnaire to complete and comment upon. A few minimal changes were made to the questions regarding the individual and the company; no corrections were made on the role ambiguity, role conflict, and job satisfaction scales. Data from subjects in the pilot study were not included in subsequent analyses.

\subsubsection{Convergent and discriminant validity}

In addition to the attitudinal measures all having Cronbach alpha levels above 0.80 , we also tested if indeed they represented separate constructs. Using confirmatory factor analysis, we tested if role ambiguity, role conflict, and job satisfaction were best rep-resented by a three-factor structure, as opposed to a two- or one-factor structure. Results do indeed support the construct validity of our measures. The three-factor model was significantly better fitting than the one-factor model $\left(\Delta \mathrm{X}^{2}=\right.$ 228.47; $\mathrm{df}=3 ; \mathrm{p}<.0001)$. It also had better fit than all three possible two factor models: of role-ambiguity and job conflict loading onto the same factor $\left(\Delta \mathrm{X}^{2}=48.66 ; \mathrm{df}=2 ; \mathrm{p}<.0001\right)$; of role-ambiguity and job satisfaction loading on the same factor $\left(\Delta \mathrm{X}^{2}=162.83 ; \mathrm{df}=2 ; \mathrm{p}<.0001\right)$; and job conflict and job satisfaction loading onto the same factor $\left(\Delta X^{2}=191.50 ; \mathrm{df}=2 ; \mathrm{p}<.0001\right)$. Furthermore, the three factor solution had good empirical fit (e.g., RMSEA $=0.06$ ). Altogether, this gives us good confidence that our constructs had the intended psychometric characteristics.

\section{Findings}

Summary statistics for the study's variables are reported in Table 2. From these simple statistics, a number of preliminary findings emerge that merit some discussion.

The average level of role conflict (mean $=3.24 ; S D=0.67$ ) and role ambiguity (mean $=2.74 ; S D=$ 0.81) are comparable to, although somewhat lower than, the levels of these constructs perceived in other industries. More specifically, as is shown in Fig. 1, the levels of role ambiguity and role conflict that spa managers perceived were somewhat less than other professions, with the exception 
Table 2

Summary statistics.

\begin{tabular}{|c|c|c|c|c|c|c|c|c|c|c|c|c|c|}
\hline & Mean & SD & 1 & 2 & 3 & 4 & 5 & 6 & 7 & 8 & 9 & 10 & 11 \\
\hline 1. Female & 0.71 & 0.45 & 1.00 & & & & & & & & & & \\
\hline 2. Age & 3.58 & 0.20 & -.04 & 1.00 & & & & & & & & & \\
\hline 3. Spa experience & 2.31 & 0.60 & -.06 & .50 & 1.00 & & & & & & & & \\
\hline 4. Assistant & 0.07 & 0.25 & -.10 & -.12 & -.06 & 1.00 & & & & & & & \\
\hline 5.Regional or group & 0.12 & 0.33 & -.13 & 32 & 25 & -.10 & 1.00 & & & & & & \\
\hline 6.N supervise & 3.01 & 0.76 & -.02 & .17 & 22 & -.18 & .18 & 1.00 & & & & & \\
\hline 7.Spa company & 0.36 & 0.48 & .08 & -.02 & -.06 & -.05 & -.09 & -.16 & 1.00 & & & & \\
\hline 8. Job satisfaction & 5,72 & 1,17 & .06 & .01 & .03 & -.08 & -.02 & .02 & -.13 & 1.00 & & & \\
\hline 9. Outsourced & 0.30 & 0.46 & .06 & -.00 & -.12 & -.07 & .08 & -.08 & .54 & .01 & $(.88)$ & & \\
\hline 10. Role ambiguity & 2.74 & 0.81 & -.08 & .06 & .00 & .08 & .10 & .01 & .00 & -.61 & .07 & $(.80)$ & \\
\hline 11. Role conflict & 3.24 & 0.67 & -.06 & .09 & -.03 & .09 & .09 & .04 & -.09 & -.52 & .01 & .77 & (.80) \\
\hline
\end{tabular}

Notes: $N=163$. Correlations greater than .15 are significant at $p<.05$.

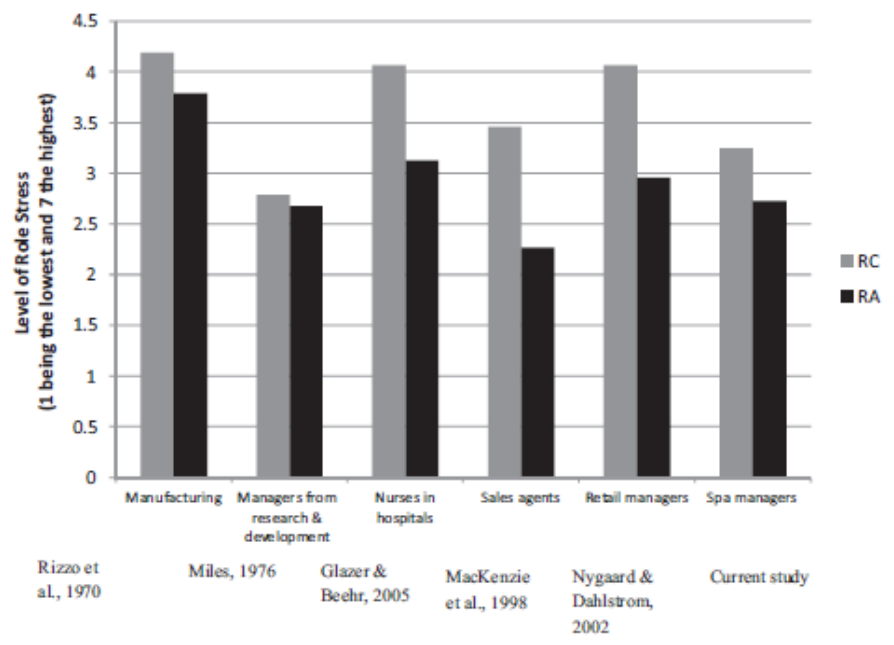

Fig. 1. Comparison of role stress levels in other industries (MacKenzie et al., 1998).

being them being higher than research and development managers. Values of role conflict ranged from 1.07 to 5.13; values for role ambiguity ranged from 1.00 to 5.29 . This provides some support for previous authors who have suggested that the hospitality industry can be a stressful one for its employees (e.g., Papadopoulou-Bayliss et al., 2001) and confirms that spa managers do experience both role stressors, but it also shows that there is significant variability in the levels of role stressed perceived by spa managers in the industry.

Examination of the correlations in Table 2 also is somewhat interesting. At first glance, it does not appear that outsourcing plays a role in determining the levels RA and RC as there are no significant effects. Specifically, the correlations between being outsourced and role ambiguity and role conflict were non-significant ( $r$ 's of 0.07 and 0.01 respectively). Although the mean levels of role ambiguity and role conflict were nominally higher in the outsourced vs. non-outsourced groups (means of 2.8 vs. 2.7 for role conflict, and 3.3 vs. 3.2 for role ambiguity), the differences were not significant $(p=.46$ and $p=$ .19 respectively).The hypothesized effects, however, could be hidden or suppressed by associated variables related to the company and/or manager, and thus we employed a multivariate analysis to formally test our hypotheses. 
Table 3

Regression results,

\begin{tabular}{|c|c|c|}
\hline & Role ambiguity & Role conflict \\
\hline Intercept & $4.28(1.05)^{-7}$ & $3.80(1.21)^{m-m}$ \\
\hline Gender & $-0.028(0.11)$ & $0.0012(0.13)$ \\
\hline Age & $0.28(0.31)$ & $-0.55(0.035)$ \\
\hline Spa experience & $-0,0077(0,098)$ & $-0.11(0.11)$ \\
\hline Assistant & $0.16(0.21)$ & $0.23(0.24)$ \\
\hline Regional or group & $0.068(0.17)$ & $0.062(0.20)$ \\
\hline $\begin{array}{l}\text { Number of people } \\
\text { supervised }\end{array}$ & $0.0066(0,070)$ & $0.037(0.080)$ \\
\hline $\begin{array}{l}\text { Surveyed through a } \\
\text { spa company }\end{array}$ & $-0.27(0.13)^{*}$ & $-0.40(0.15)^{-\pi}$ \\
\hline Job satisfaction & $-0.44(0.044)^{-m}$ & $-0.41(0.050)^{-m+}$ \\
\hline $\begin{array}{l}\text { Outsources ( } 1 \text { = yes, } \\
0=\text { no) }\end{array}$ & $0.30(0.13)^{\circ}$ & $0.25(0.15)^{\circ}$ \\
\hline$R$-square & 0,42 & 0.33 \\
\hline
\end{tabular}

Notes: $N=166$. Age, spa experience, and number of people supervised were all transformed using a logarithm because the distributions were positively skewed. However, the effects were not notably different either transformed or untransformed (the effect of age was not marginally significant when non-transformed) and did not change the nature of the significant results that were found.

$p<, 05$.

" $p<.01$,

-.. $p<, 001$.

We thus ran a multiple regression (see Table 3) that controlled for nine different variables. After doing this, and in particular after controlling for the effects of job satisfaction, the analysis revealed the hypothesized negative effect that outsourcing has on both RA and RC. Job satisfaction is strongly related to both role ambiguity and role conflict (respectively, correlations of -0.61 and -0.52 , and $B$ coefficients of -0.44 and -0.41 , all significant at $p<.001$; see Tables 2 and 3 ).Job satisfaction is notably negatively related to role ambiguity and role conflict. Yet, these results suggest that, if one compares two workers who like their jobs similarly, those in an outsourced relationship will experience more role ambiguity ( $B$ $=0.30, p<.001)$ and more role conflict $(B=0.25, p<.05)$. The results thus support our hypotheses.

In addition to our specific hypothesis testing, we also felt the regression presented some interesting additional findings. Most notably, those who were contacted through a spa company reported significantly less role ambiguity and role conflict and those surveyed through their hotels. Note that while those contacted via a spa company were more likely to be outsourced ( $r=.54)$, both groups had individuals who were outsourced and not, so the method of contact was not a proxy for being outsourced. It is not fully clear what this finding means, and may indicate an area in need of more research. The findings, though, are consistent with prior research that suggests the importance of quality communications (Kahn et al., 1964; Rizzo et al., 1970; Walker et al., 1975). Although we did not test it, it seems very likely that spa managers, outsourced or not, are in regular communication with management at the hotel because of their proximal location; communication with an associated off-site spa company is more questionable. This finding may indicate that spa managers who have a closer relationship with the parent spa company, regardless of being outsourced or not, get a level of communication and support those with this more distal relationship experience. Put another way, spa managers who were close-enough with the spa company such that the spa company were willing and able to forward them our questionnaire enjoyed less role conflict and role ambiguity than those spa managers for whom the hotel provided the questionnaire. While often control variables in analyses are ignored (Spector and Brannick, 2011), this notable relationship may indicate that future research should 
delve more deeply into the sort of communication spa managers have in their role-spanning relationships.

\section{Discussion}

\subsection{Role conflict}

This study confirmed that there is greater role conflict associated with the management of outsourced hotel spas than with proprietarily managed hotel spas. One of the primary reasons that role conflict arises in organizations is due to an employee's interaction with multiple stakeholders who often have conflicting expectations of that employee (Kahn et al., 1964; Fields, 2002; Onyemah, 2008). The extent to which one enjoys these interactions may help alleviate the stressors they can create, which is indicated by the need to control for job satisfaction in order to reveal the effect that outsourcing has on role conflict. Yet affect aside, receiving different instructions can lead to uncertainty and inconsistency about organizational objectives and goals (Gross et al., 1958). As with studies on 'boundary relevance' which have studied how boundary spanners must interact with supervisors from multiple organizations (e.g., Kahn et al., 1964; Nygaard and Dahlstrom, 2002), in outsourced spas the managers must have frequent contact with management personnel from both within and outside their organization. In other words, the manager in the outsourced spa must interact not only with executives from the spa company, but also with management personnel from the hotel property and/or hotel management company. In proprietarily managed spas, however, there is only the one internal management team with whom the manager must work.

Because general managers are said to rarely understand the complexity of managing the spa department, yet are ultimately responsible for its success, they are likely to involve themselves in important decisions about the spa which can impact the hotel, even if this spa is overseen by an external firm. This then places the spa manager in the difficult situation of being subject to the instructions, objectives and/or demands of superiors from two different firms, each of which likely has its own preferences. Unlike the GM who is primarily interested in growing the bottom-line, the spa manager and the spa management company also emphasize the importance of learning and growth, leadership development and employee satisfaction (Bjurstam and Cohen, 2008) which is often of secondary importance to hotel GMs, especially when the spa staff are the responsibility of an external organization. The specialist firm, meanwhile, is more prone to consider the long-term satisfaction and development of its staff as paramount to its success.

\subsection{Role ambiguity}

Our results also supported the notion that managers of out-sourced spas experience higher degrees of role ambiguity than do managers of spas which are managed by the hotel itself. Again, the extent to which spa managers enjoy their job play an important role and can obscure the effect that outsourcing has on role ambiguity. Nonetheless, spa managers who work with a third party were less certain about what was expected of them, and what their goals, objectives, and responsibilities were, than were managers of proprietarily managed spas. Previous research suggests that this may in part be due to the lack of daily, on-property assistance provided by third parties (Jones, 1997) as this can impact the frequency and quality of communication, supervision and feedback.

As communication frequency and information availability have been correlated with levels of role ambiguity (Kahn et al., 1964), and as quality communication in outsourced businesses and for boundary spanners may suffer, this can be seen as one explanation for the higher role ambiguity in outsourced spas. This is particularly likely since the spa manager is based at the hotel and away from the spa company's headquarters, which are often in different countries, thus making communication more challenging for these spa man-agers than for their counterparts who work more closely with the hotel's 
management. Again, this may also be why those who were surveyed through the spa companies reported, on average, lower levels of role ambiguity.

Role ambiguity is also likely higher in outsourced scenarios because these managers have more than one direct supervisor which can lead to them not receiving enough specific guidance or clear instructions, both of which have been found to increase role ambiguity (Walker et al., 1975). For example, while most spa man-agers have a technical therapist background, and can receive clear guidance on this aspect of their job from the spa company, such managers often lack sufficient business management skills and training (Bjurstam and Cohen, 2008; ISPA, 2012; SRI International, 2012), and must often rely on the hotel's management personnel for such guidance. As the outsourced spa manager works for the external organization, they may not receive as much support as those who manage spas directly for the hotel, and as such their role ambiguity is higher.

Managers of outsourced hotel spas must also satisfy both the hotel and spa's expectations and thus may face a lack of clear, coherent and formalized goals and objectives. As this has been shown to increase the level of role ambiguity in studies of other boundary spanners, it may also explain some of the results found here. That is, if they do not have clear expectations or understanding of what their role is and what they are held responsible for, they will hesitate to make decisions and will feel torn about where the limits of their job are (Kahn et al., 1964).

\section{Conclusion}

Interest has grown about the impact of organizational practices on work-related stress because organizations influence how such stress emerges and affects outcomes (Singh et al., 1996). Understanding the relationship between organizational structures and role stressors can assist firms in creating less stressful environments as well as improving boundary spanners' effectiveness (Churchill et al., 1976; Singh et al., 1996; Stamper and Johlke, 2003). While such areas as professional and cultural controls, formalization, and centralization have been investigated for their impact on role stress, the implications of outsourcing have not. Although some researchers have suggested that these role stressors may be greater in outsourced service industry relationships due to increased task interdependence (Chung and Schneider, 2002; Fisher et al., 2008) empirical evidence of whether this is in fact the case has been lacking.

This study investigated the relative levels of the two role stressors in managers of hotel spas that were outsourced as compared with those that were managed by the hotel. Higher levels of role ambiguity and role stress were expected in spa managers of outsourced spas due to their greater levels of task interdependency and boundary spanning responsibilities. This was an important issue to examine in hotel spas since outsourcing is becoming an increasingly popular strategic decision for hotels. In addition, given the costs associated with high levels of manager turnover in the spa industry, it was deemed critical to examine some of the potentially underlying causes for these role stressors, a common reason managers leave their employers. The goal of this study, therefore, was to look into some theoretically plausible but largely untested empirical propositions for the degree of role conflict and role ambiguity as perceived by spa managers in outsourced and proprietarily managed hotel spas. The findings which confirmed these propositions provides support for the notion that people in outsourced situations can experience higher levels of stress associated with their role due to the increased task interdependence, boundary spanning and organizational implications of outsourcing.

\subsection{Managerial implications}

The results of our study should be valuable in several ways too hotel and spa managers, and the companies for whom they work. One implication of our findings is that these companies should pay greater attention to the causes underlying the role ambiguity and role conflict experienced by spa 
managers. As these role stressors are known to increase employee turnover, and as this is a particular problem in the spa industry, firms that take steps to reduce ambiguity and conflict amongst spa managers should assist firms in tackling one of their greatest problems. For example, these firms could improve role clarity and communication frequency as ways to decrease their managers' role stress and thus job dissatisfaction.

As the levels of role ambiguity and role conflict were significantly higher in outsourced spas, particular attention should be paid to their causes in such organizations. One recommendation is that such firms should adhere to the principles of unity of command as this too can reduce the likelihood of role stress. This helps to ensure that responsibilities are fixed and expectations are clear, and eliminates the need to satisfy multiple stakeholders with potentially incompatible expectations and requirements.

It is again worth noting, though, that the effects for outsourcing on the role stressors were revealed only after controlling for the effects of job satisfaction. This indicates that job satisfaction may play a particularly important role in boundary-spanning contexts. A key implication for practice from this is that, when hiring spa managers, companies (both hotels and spa companies) need to pay particular attention to the issue of person-job fit (Kristof-Brown et al., 2005).

Another implication of the greater level of role stressors in out-sourced spas is that potential spa managers may be advised to consider the type of organization with which they pursue their career. That is, such managers may be more suited for spas that are managed by either the spa company or the hotel depending on whether they believe they have the ability to balance the needs of two organizations. Similarly, firms recruiting spa managers are advised to consider this in their selection process.

\subsection{Limitations}

This study has several important possible limitations to consider. First, as the survey was distributed globally and only in English, it was most likely answered by non-native English speakers and thus misinterpretation and misunderstanding of the items in the survey may have resulted in construct irrelevant variance which can affect the correlation between variables (Saunders et al., 2009). However, as the respondents work in an industry where managers must demonstrate proficient levels of English, this limitation was considered to be negligible. Our confirmation of the convergent and discriminant validity of the attitudinal constructs in our study also suggests that this did not occur.

There exist very few academic studies in the spa industry, and particularly with regards to role stressors, and this study helps to fill these voids. However, due to the dearth of the research, the researchers had to inform themselves about the state of the spa industry through trade articles which may not be as reliable or objective as academic studies. However, since the interviewees are experts in the field, the researchers felt comfortable with their interpretations and explanations of the inner workings of the industry. Nonetheless, we hope that this research helps encourage more academic focus on the sorts of issues facing the spa industry.

Despite that fact that the response rate lies above the average for internet questionnaires, particularly when each response is from a manager at a different organizational unit, it is still less than desirable. Therefore, the representativeness of respondents may not be reflective of the population and broad generalization should not be made (Lozar Manfreda et al., 2008). As noted, given the international and cross-organizational nature of the study, the response rate was deemed acceptable, but it would again be useful for future research to pursue different methods of sampling to help reveal the population's characteristics.

Outsourcing can take on my forms, and within the spa industry numerous alternative arrangements between hotel owners, management companies and spa organizations exist. One further limitation of 
the study, therefore, was the lack of questions designed to uncover more of the specifics about each outsourced spa's specific relationship to the hotel. Such information would have provided for a richer study, and again represents a fruitful area for future research.

\subsection{Suggestions for future research}

While the limitations noted above present opportunities for future research to help test the generalizability of our results, our findings also indicate some areas where future research can continue to develop knowledge about this critical management decision. This study has attempted to add to the scare literature about spas and about outsourcing in hotel management which is notably rare given the popularity of spas and the use of outsourcing in the industry (Gonzalez et al., 2011). We thus provide several recommendations for future research, which we describe below.

There is still great potential to conduct research in the area of outsourcing, specifically in the hotel industry. An interesting topic for future studies would be to look at why hotels are choosing to outsource their spa operations/management more frequently. Furthermore, it may be worthwhile to look at the impact of outsourcing on spa profits to identify if outsourcing helps to improve the bottom line.

As previously mentioned, numerous alternative outsourcing structures exist between hotels and spas and given this study's finding that role stress was greater in outsourced spas, it would be worthwhile to investigate if the level of role stressors varies across these structures. In addition, a further study could investigate which practices (from the hotel and/or spa companies) help to attenuate the level of role stress experienced by spa managers.

A further interesting question worthy of further study would be to examine whether those spa managers who also sit on the executive board of the hotel company experience different degrees of role ambiguity and role conflict. Such managers may have a clearer understanding of the hotel itself, and of the spa's role within it, and as such may in fact experience lower levels of these role stressors.

The lack of academic research in the spa industry meant that the researchers were unable to compare their findings with previous studies about spa managers. Because this study examines hypotheses in the spa industry which have not been previously tested, future replications and extensions would be welcome in order to increase the generalizability and applicability of the findings reported in this study.

\section{References}

Adler, P., 2003. Making the HR sourcing decision. MIT Sloan Management Review 45(1), 53-60.

Aldrich, H., Herker, D., 1977. Boundary spanning roles and organizational structure. TheAcademyofManagement Revie 2 (2), 217-230.

Anderson, P.C., 2011. Spas and the lodging industry. In: O'Fallon, M.J., Rutherford, D.G.(Eds.), Hotel Management and Operations.JohnWiley \& Sons, Inc., Hoboken, NJ, pp. 39-54 (Chapter 1.6).

Andrews, R., 2009. Sub contracting a hotel spa: a good idea or a nightmare? Spa Management (January), 82-84.

Benson, J., 1998. Dual commitment: contract workers in Australian manufacturing enterprises.Journal ofManagement Studies 35 (3), 355-375.

Bettis, R., Bradley, S., Hamel, G., 1992. Outsourcing and industrial decline. Academy of Management Executive 6(1), 7-22. 
Bjurstam, A., Cohen, M., 2008. Spas and the future leadership climate. In: Cohen, M., Bodeker, G. (Eds.), Understanding the Global Spa Industry: Spa management. Butterworth Heinemann, Oxford, pp. 363-376 (Chapter 21).

Brown, S., Peterson, R., 1993. Antecedents and consequences ofsalesperson job sat-isfaction: a metaanalysis and assessment of causal effects.Journal ofMarketing 30, 63-77.

Burgess, R., 2011. The Benefits of Looking Outwards. Hotel Management, Available at: http://www.hotelmanagement-network.com/features/feature116200

Chung, B., Schneider, B., 2002. Serving multiple masters: role conflict experienced by serviceemployees.Journal ofService Marketing 16(1), 70-87.

Churchill, G., Ford, N., Walker, O., 1976. Organizational climate and job satisfaction in the salesforce. Journal of Marketing Research 13, 323-332.

Corwin, R.G., 1969. Patterns oforganizational conflict.Administrative Science Quar-terly 14, 507-521.

DeRoos, J.A., 2011. Gaining maximum benefit from franchise agreements, manage-ment contracts, and leases. In: Sturman, Corgel,Verma(Eds.), The CornellSchool of Hotel Administration on Hospitality. John Wiley and Sons, New York, pp.

293-308 (Chapter 19).

Donada, C., Nogatchewsky, G., 2009. Emotions in outsourcing: an empirical study in the hotel industry. InternationalJournal ofHospitality Management, 367-373.

Dusseau, R., Brennan, M.W., 2008. Spa feasibility: steps and processes. In: Cohen, Bodeker (Eds.), Understanding the Global Spa Industry: Spa management. But- terworth Heinemann, Oxford, pp. 110129 (Chapter 7).

Espino-Rodriguez, T., Padron-Robaina, V., 2005. Outsourcing and its impact on oper-ational objectives ofservices: an empirical examination ofthe hotel sector. The Services Industries Journal 25 (5), 689-708.

Espino-Rodriguez, T.,Gil-Palida,A., 2005. The relationship between leisure outsourc-ing and specificity performance and management perception in hotels in the Canary Islands. Journal ofHospitality and Tourism Research 29 (3), 396-418.

Euromonitor International, 2012. Health and Wellness Tourism: Market Size, Retrieved from: GMID: Global Market Information Database.

Fields, D., 2002. Taking the Measure ofWork: A Guide to Validate Scales for Organi-zational Researc and Diagnosis. SAGE Publications, Thousand Oaks, CA.

Fisher, S., Wasserman, M., Wolf, P., Wears, K., 2008. Human resource issues in out-sourcing: integrating research and practice. Human Resource Management 47 (3), 501-523.

Garrow,J., 2008.Spaindustrybenchmarking. In: Cohen, Bodeker(Eds.),Understand- ing the Global Spa Industry: Spa Management. Butterworth Heinemann, Oxford, pp. 56-65 (Chapter 4).

Gibson, A., 2008. Business plans for"state ofthe art" spas. In: Cohen, Bodeker(Eds.), Understanding the Global Spa Industry: Spa Management. Butterworth Heine- mann, Oxford, pp. 87-109 (Chapter 6).

Gilley, K., Rasheed, A., 2000. Making more by doing less: an analysis ofoutsourcing and its effects on firm performance. Journal ofManagement, 763-790.

Glazer, S., Beehr, T.A., 2005. Consistency of the implications of three role stressors across fourcountries.Journal of Organizational Behavior 26,467-487. 
Glover, L., 2012. Hotel Spa: The Pros and Cons of Sub-contracting Spa Operations, Available at: http://hotelexecutive.com/business_review/2974/hotel-spa-the- pros-cons-of-subcontracting-spaoperations (retrieved 20.05.12).

Gonzalez, R., Llopis,J., Gasco,J., 2011.What dowe know about outsourcing in hotels? The Service IndustriesJournal31 (1), 1669-1682.

Gross, N., Mason, W.S., McEachern, A.W., 1958. Explorations in role analysis. Studies ofthe school superintendency role. Wiley, New York.

Hemmington, N., King, C., 2000. Key dimensions of outsourcing hotel food and bev-erage services. InternationalJournal of Contemporary Hospitality Management 12(4), 256-261.

House, R., Rizzo, J., 1972. Role conflict and ambiguity as critical variables in a model oforganizational behavior. Organizational Behavior and Human Performance 7, 467-505.

Ilgen, D., Hollenbeck, J., 1991. The structure of work: job design and roles. In: Dunnette, M., Hough, L. (Eds.), Handbook of Industrial and Organizational Psy-chology. Consulting Psychologists Press, Palo Alto, pp. 165-207.

International SPA Association, 2012. The International SPA Association's 2012 Spa Industry Study. International SPA Association.

International SPA Association, n.d. Type of Spas, Available at: http://www. experienceispa.com/ISPA/Visit/Spa+101/Types+of+Spas.htm

Jones, W., 1997. Outsourcing basics. Information System Management 14, 66-69.

Kahn, R., Wolfe, D., Quinn, R., Snoek, J., Rosenthal, R., 1964. Organizational Stress. John Wiley and Sons, New York.

Karasek, R., 1979.Job demands,job decision latitude, and mental strain: implications for job redesign. Administrative Science Quarterly 24, 285-306.

Keegan, S., Lucas Rosemary, L., 2005. Hospitality to hostility: dealing with low response rates in postal surveys. International Journal of Hospitality Manage-ment 24(2),157-169.

Kristof-Brown, A.L., Zimmerman, R.D., Johnson, E.C., 2005. Consequences of indi-viduals' fit at work: a meta analysis of person-job, person-organization, person-group, and person-supervisor fit. Personnel Psychology 58, 281-342.

Ladkin, A., 1999. Hotel general managers: a review of prominent research themes. InternationalJournal ofTourism Research 1 (3), 167-193.

Lam, T., Han, M., 2005. A study of outsourcing strategy: a case involving the hotel industry in Shanghai, China. International Journal of Hospitality Management 24 (1), 41-56.

Lambert, D.M., Emmelhainz, M.A., Gardner,J.T., 1996. Developing and implementing supplychain partnerships.The InternationalJournal ofLogistics Management 7 (2), 1-17.

Lamminmaki, D., 2011. An examination of factors motivating hotel outsourcing. International Journal ofHospitality Management 30, 963-973.

Lei, D., Hitt, M., 1995. Strategic restructuring and outsourcing: the effect ofmergers and acquisitions and LBOs on building firm skills and capabilities Journal of Management 21 (5), 835-859. 
Lozar Manfreda, K., Bosnjak, M., Berzelak, J., Haas, I., Vehovar, V., 2008. Web sur-veys versus other survey modes: a meta-analysis comparing response rates. InternationalJournal ofMarket Research 17 (5), 79-104.

MacKenzie, S.B., Podsakoff, P.M., Ahearne, M., 1998. Some possible antecedents and consequences of in-role and extra-role salesperson performance. Journal ofMarketing 62, 87-98.

Mandelbaum, R., Lerner, G., 2008. PKF industry analysis: hotel operators massage more profits from their spa operations. Cornell Hospitality Quarterly 49 (2), 99-104.

Miles, R.H., 1976a.Acomparison ofthe relative impacts of role perceptions ofambi- guity and conflict by role. Academy ofManagementJournal 19, 25-35.

Miles, R.H., 1976b. An empirical test of causal inference between role perception of conflict and ambiguity and various personal outcomes. Journal of Applied Psychology60, 334-339.

Nunnally, J., 1978. Psychometric Theory. McGraw Hill, New York.

Nygaard, A., Dahlstrom, R., 2002. Role stress and effectiveness in horizontal alliances. Journal ofMarketing 66, 61-82.

Onyemah, V., 2008. Role ambiguity, role conflict, and performance: empirical evi-dence of an invertedU relationship. Journal of Personal Selling and Sales Management 18 (3), 299-313.

Papadopoulou-Bayliss, A., Ineson, E.M., Wilkie, D., 2001. Control and role conflict in food service providers. InternationalJournal ofHospitality Management 20 (2), 1-13.

Paxson, M., 1995. Increasing survey response rates: practical instructions from the total-design method. Cornell Hospitality Quarterly 36 (4), 66-73.

PKF Hospitality Research, 2012. Trends Report.

Preston, D., 2011. Reducing Employee Turnover: Five Values That Will Help You Build Loyalty and Contentment. Spa Trade, Available at: http://www.spatrade. com/spa-business/reducing-employeeturnover-five-values-will-help-you- build-loyalty-and-contentment (retrieved 04.01.12).

Quelin, B., Duhamel, F., 2003. Bringing together strategic outsourcing and corporate strategy: outsourcing motives and risks. European Management Journal 21 (5), 647-661.

Quinn, R., Shepard, L., 1974. The 1972-73 Quality ofEmployment Survey. Michigan Survey Research Center of the Institute for Social Research, Ann Arbor.

Rogers, D.L., Molnar, J., 1976. Organizational antecedents of role conflict and ambiguity in top-level administrators. Administrative Science Quarterly 21, 598-610.

Rothery, B., Robertson, I., 1995. The Truth About Outsourcing. Gower Publishing, Hampshire.

Rousseau, D.M., 2006. Is there such a thing as evidence-based management? AcademyofManagement Review31, 256-269.

Rousseau, D.M., McCarthy, S., 2007. Educating managers from an evidence-based perspective. Academy of Management Learning and Education 6, 94-101.

Rizzo,J., House, R., Lirtzman, S., 1970. Role conflict and ambiguity in complex orga-nizations. Administrative Science Quarterly 15 (2), 150-163.

Sanders, Locke, Moore,Autry, 2007.Amultidimensional frameworkforunderstand- ing outsourcing arrangements. TheJournal ofSupplyChain Management Fall 43 (4), 3-15. 
Saunders, M., Lewis, P., Thornhill, A., 2009. Research Methods for Business Students, 5th ed. Pearson Education, Harlow.

Singer,J., Monteson, P., 2006. First International Spa Benchmarks. Hospitality Inside.

Singer, J., 2011. Global spa trends: are you on course? HotelNewsNow.com, Available at:

http://www.hotelnewsnow.com/Articles.aspx/5430/Global-spa- trends-Are-you-on-course (retrieved 07.07.12).

Singh, J., 1993. Boundary role ambiguity: facets, determinants, and impacts. Journal ofMarketing 57(2), 11-31.

Singh,J., 1998. Striking a balance in boundary-spanning positions: an investigation of some unconventional influences of role stressors and job characteristics on job outcomes of salespeople. Journal ofMarketing 62, 69-86.

Singh,J., Rhoads, G., 1991. Boundary role ambiguity in marketingoriented positions: a multidimensional, multifaceted operationalization. Journal of Marketing Research 28 (August), 328-338.

Singh, J., Verbeke, W., Rhoads, G.K., 1996. Do organizational practices matter in role stress processes? A study of direct and moderating effects for marketing- oriented boundary spanners.Journal ofMarketing 60,69-86.

Spector, P.R., Brannick, M.T., 2011. Methodological urban legends: the misuse of statistical control variables. Organizational Research Methods 14, 287-305.

Solli-Saether, H., 2011. Transplants' role stress and work outcome in IT out-sourcing relationships. Industrial Management and data Systems 111 (2), 227-245.

Stamper, C.L., Johlke, M.C., 2003. The Impact of perceived organizational support on the relationship between boundary spanner role stress and work outcomes. Journal ofManagement 29 (4), 569-588.

SRI International, 2012. Spa Management Workforce and Education: Addressing Market Gaps. Global Spa Summit, Arlington, VA.

Tabacchi, M.H., 2010. Current research and events in the spa industry. Cornell Hos- pitalityQuarterly51 (1), 102-117.

Taplin, R., 2007. Outsourcing and human resource management: an international survey. Routledge, NewYork.

Teas, K., 1980. An empirical test of linkages proposed in the Walker, Churchill, and Ford model of salesforce motivation and performance. Journal of the Academy of Marketing Science 8 (1), 58-72.

Thompson, J., 1967. Organizations in Action. McGraw-Hill, New York.

Van Mieghem,J.A., 1999. Coordinating investment, production and subcontracting. Management Science 45 (7), 954-971.

Walker, O., Churchill, G., Ford, N., 1975. Organizational determinants of the industrial salesman's role conflict and ambiguity. Journal of Marketing 39, 32-39.

White, P.E., 1974. Organizational studies: do they require separate conceptualiza-tions? Administration and Society6, 107-155.

Wong, S., DeSanctis, G., Staudenmayer, N., 2007.The relationship betweentaskinter- dependencyand role stress: a revisit ofthejob demands-control model.Journal of Management Studies 44 (2), 284-303. 